\title{
Is malignant hyperpyrexia muscle denervated?
}

\author{
R. F. W. MO U L D S \\ From the University Department of Medicine, The Royal Melbourne Hospital, Parkville, Victoria, \\ Australia
}

SUMMARY To test the hypothesis that human muscular dystrophies may be secondary to denervation, the responses in vitro of muscle in human malignant hyperpyrexia to electrical and pharmacological stimuli have been compared with those of the denervated mouse soleus muscle. The results suggest that the muscle abnormality in malignant hyperpyrexia is different from that produced by denervation. This must cast doubt on the concept that other human muscular dystrophies are secondary to denervation.

Electromyographic studies have suggested that the primary defect in a variety of muscular disorders may be in the motor nerve (McComas et al., 1974). From this has arisen the concept that many inherited myopathies may be due to partial denervation. The syndrome of malignant hyperpyrexia under general anaesthesia is known to occur in patients who have an underlying inherited myopathy (Isaacs and Barlow, 1970; King et al., 1972). This may have no clinical manifestations but susceptible patients usually have a raised blood level of creatine phosphokinase, and muscle from susceptible patients has been shown to be supersensitive to a variety of drugs, including succinylcholine, halothane, and caffeine (Kalow et al., 1970; Ellis et al., 1971; Moulds and Denborough, 1974).

It is well known that one of the consequences of denervation of muscle is the development of extrajunctional cholinergic receptors (Thesleff, 1974). This makes denervated muscle abnormally sensitive to succinylcholine. Denervated muscle has also been reported to be abnormally sensitive to caffeine (Gutman and Sandow, 1965). These obvious similarities between the pharmacological responses of denervated muscle and that of malignant hyperpyrexia seem to support the concept that the myopathy of the latter disorder may be a manifestation of partial denervation.

This study explores this concept in more detail, and compares a variety of responses of denervated

Address for correspondence and reprint requests: University of Melbourne, Department of Medicine, The Royal Melbourne Hospital, Parkville, Victoria 3050, Australia.

Accepted 20 May 1977 mouse muscle with those of muscle in human malignant hyperpyrexia normal human muscle, and normal mouse muscle.

\section{Materials and methods}

The mouse soleus muscle was used and denervation performed six or seven days before the experiment by unilateral sciatic nerve section under pentobarbitone anaesthesia. Usually the opposite soleus was used as a control.

The human muscle specimens were prepared as previously described (Moulds and Denborough, 1974). The sample of muscle from malignant hyperpyrexia was obtained by biopsy of the quadriceps femoris of a patient whose mother had died of malignant hyperpyrexia and who was being investigated as part of the family study to identify other susceptible family members. Her in vitro muscle responses showed that she was susceptible to malignant hyperpyrexia.

The muscles were all tested in vitro at $37^{\circ} \mathrm{C}$. Isometric tension was measured using either a Statham or Grass FTO3C transducer. The composition of the bath fluid and the method of administration of drugs and electrical stimulation have been described previously (Moulds and Denborough, 1974; Moulds, 1977).

\section{Results}

Electrical and pharmacological stimuli which are thought to act at different steps of the excitationcontraction coupling mechanism of skeletal muscle were combined to compare the responses of denervated and malignant hyperpyrexia muscle. 
RESPONSES TO SUCCINYLCHOLINE

Succinylcholine had little or no effect on either the normal human or normal mouse soleus muscles. The denervated muscles, however, gave large phasic contractures on exposure to succinylcholine, and the response to both electrical stimulation and exposure to $80 \mathrm{mmol} . \mathrm{l}^{-1}$ potassium chloride (which normally produced a large contracture) was abolished (Fig. 1). This suggests that the denervated muscle cell membrane had been

\section{Normal}

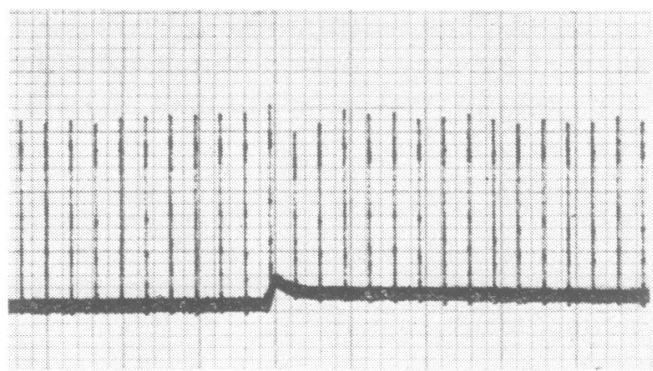

Denervated
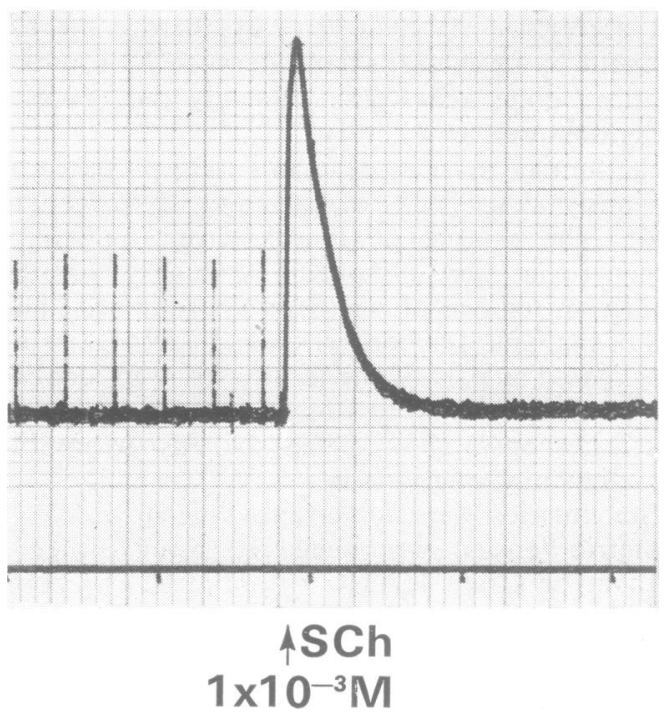

Fig. 1 Examples of the response to exposure to succinylcholine (SCh) of normal (upper panel) and denervated (lower panel) soleus muscle. The figure also shows the twitch response to direct electrical stimulation which, in the normal muscle, was virtually unaffected by succinylcholive but which, in the denervated muscle, was immediately abolished by succinylcholine. The time marker in lower panel is in minutes. depolarised by succinylcholine. In contrast to this, the contracture produced in malignant hyperpyrexia muscle by succinylcholine was not associated with loss of response to either electrical stimulation or exposure to potassium chloride.

\section{RESPONSES TO HALOTHANE AND CAFFEINE}

Unlike malignant hyperpyrexia muscle, the denervated mouse muscles were not more sensitive than normal to exposure to halothane (Fig. 2). Similarly, caffeine $\left(1.0 \mathrm{mmol} . \mathrm{1}^{-1}\right)$ enhanced the electrically stimulated twitch to a similar extent in both the normal and denervated solei. The threshold concentration of caffeine $\left(8.0 \mathrm{mmol} . \mathrm{1}^{-1}\right)$ required to produce a contracture was the same in both the denervated and normal soleus muscles. Contractures produced by larger concentrations of

\section{Normal}

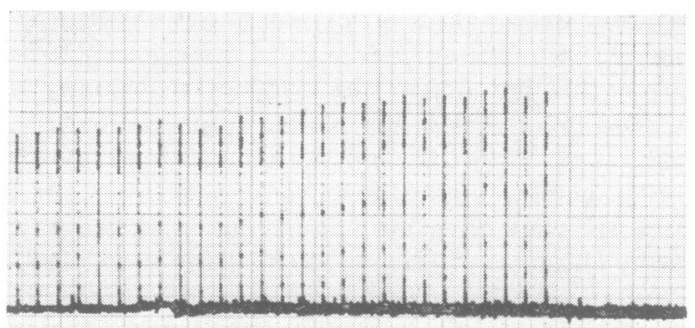

\section{Denervated}
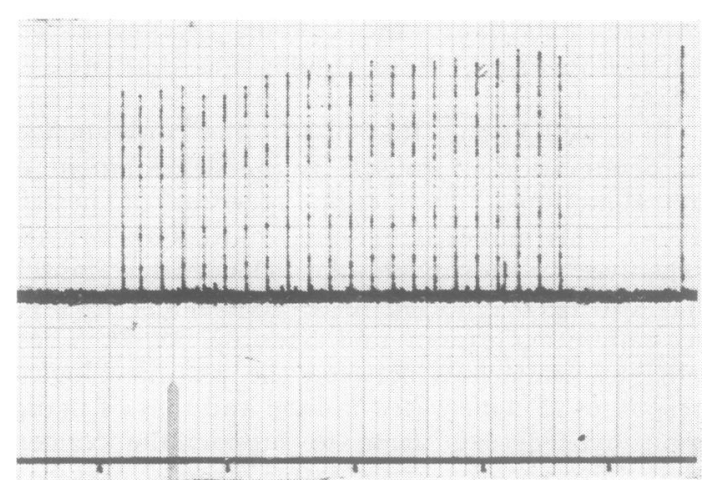

\section{A Halothane}

Fig. 2 Examples of the response to exposure to halothane of normal (upper panel) and denervated (lower panel) soleus muscle. The figure also shows the slight increase in the twitch response to direct electrical stimulation which was produced in both soleus muscles by halothane. The time marked in the lower panel is in minutes. 
caffeine, however, developed more rapidly in the denervated muscles.

\section{RESPONSES TO ELECTRICAL STIMULATION}

The denervated muscles had an increased twitch to maximum tetanus ratio ( $\mathrm{T} / \mathrm{Po})$, a delayed relaxation measured as the time from the last stimulus of a maximum tetanus until $5 \%$ relaxation had occurred (SF 0.95), and a decreased frequency of stimulation required to produce half the maximal tetanic tension $(\mathrm{Hz} 50 \%$ ) (Table 1$)$. This suggests that denervation results in a prolonged 'active state' of the muscle occurring after depolarisation of the muscle cell membrane (Moulds, 1977). In contrast, these indices of contraction and relaxation after electrical stimulation of the malignant hyperpyrexia muscle were the same as in normal human muscle (Table 2).

Table 1 Effect of denervation of soleus muscle on indices of contraction after direct electrical stimulation

\begin{tabular}{llll}
\hline & $\begin{array}{l}\text { Normal } \\
(7)\end{array}$ & $\begin{array}{l}\text { Denervated } \\
(7)\end{array}$ & $\mathrm{P}$ \\
\hline T/Po (\%)* & $16.60 \pm 0.66 \dagger$ & $26.30 \pm 0.94$ & $<0.001$ \\
SF 0.95 (ms) & $26.71 \pm 1.35$ & $35.00 \pm 0.89$ & $<0.001$ \\
Hz 50\% (Hz) & $27.56 \pm 0.92$ & $19.69 \pm 0.44$ & $<0.001$ \\
\hline
\end{tabular}

* For definition of symbols. see text.

$\dagger$ Mean \pm SEM.

Table 2 Indices of contraction after direct stimulation of malignant hyperpyrexia muscle and normal human muscle

\begin{tabular}{llll}
\hline & Normal $\dagger$ & $\begin{array}{l}\text { Malignant } \\
\text { hyperpyrexia } \ddagger\end{array}$ & P \\
\hline T/Po $(\%)^{*}$ & $17.3 \pm 1.3$ & $19.9 \pm 2.9$ & $>0.40$ \\
SF $0.95(\mathrm{~ms})$ & $55.0 \pm 2.5$ & $48.0 \pm 2.1$ & $>0.025$ \\
Hz $50 \%(\mathrm{~Hz})$ & $14.0 \pm 0.9$ & $16.0 \pm 1.0$ & $>0.10$ \\
\hline
\end{tabular}

* For definition of symbols, see text.

+ Mean + SEM of 36 preparations from 14 patients.

$\ddagger$ Mean \pm SEM of four preparations from the patient with malignant hyperpyrexia.

\section{Discussion}

These results suggest that the abnormality of muscle in malignant hyperpyrexia is at a different site of the mechanism of excitation-contraction coupling from that produced by denervation. The excitation-contraction coupling mechanism of skeletal muscle normally involves a complex series of events. Basically, however, it consists of two processes. Firstly, there is depolarisation of the cell membrane, which is initiated at the motor endplate by acetylcholine and then transmitted to the rest of the muscle fibre by the propagated action potential. Secondly, calcium ions are released into the myoplasm of the fibres, probably from the sarcoplasmic reticulum. This study suggests that denervation only results in an alteration of the first step in the excitation-contraction coupling process concerned with depolarisation of the cell membrane. This can be deduced from the findings that the two major manifestations of denervation are the contracture produced by succinylcholine, which is almost certainly caused by depolarisation of the cell membrane, and the prolonged 'active state' of the muscle after electrical depolarisation of the cell membrane, which may be due to the prolonged action potential which has been reported to follow denervation (Redfern and Thesleff, 1971).

In contrast, the abnormality in malignant hyperpyrexia muscle is probably not associated with the step of membrane depolarisation but is more likely to be associated with the second step in the excitation-contraction coupling process concerned with calcium release. This can be deduced from the following findings. Firstly, the contracture produced by succinylcholine in malignant hyperpyrexia muscle is unlike that produced in denervated muscle in that it does not result in a loss of response to electrical stimulation or potassium chloride. The contracture is, therefore, probably not caused by membrane depolarisation. Secondly, electrical depolarisation of the cell membrane of malignant hyperpyrexia muscle, unlike denervated muscle, is not associated with any alteration of the active state. Thirdly, again unlike denervated muscle, malignant hyperpyrexia muscle is abnormally sensitive to caffeine and halothane, drugs thought to cause muscle contracture by releasing calcium ions from the sarcoplasmic reticulum (Weber, 1968).

Caution must always be exercised in extrapolating from mice to men, but these findings probably exclude denervation as being the underlying muscular abnormality in malignant hyperpyrexia. The argument for the malignant hyperpyrexia myopathy being secondary to denervation was probably better than for most other myopathies, so this study must cast doubt on the concept that any human myopathies are secondary to denervation.

\section{References}

Ellis, F. R., Harriman, D. G. F., Keaney, N. P., Kyei-Mensah, K., and Tyrell, J. H. (1971). Halothane-induced muscle contracture as a cause of hyperpyrexia. British Journal of Anaesthesia, 43, 721-722. 
Gutman, E., and Sandow, A. (1965). Caffeine-induced contracture and potentiation of contraction in normal and denervated rat muscle. Life Sciences, 4, $1149-1156$.

Isaacs, H., and Barlow, M. B. (1970). Malignant hyperpyrexia during anaesthesia: possible association with subclinical myopathy. British Medical Journal, 1, 275-276.

Kalow, W., Britt, B. A., Terreau, M. E., and Haist, C. (1970). Metabolic error of muscle metabolism after recovery from malignant hyperthermia. Lancet, 2 , 895-898.

King, J. O., Denborough, M. A., and Zapf, P. W. (1972). Inheritance of malignant hyperthermia. Lancet, 1, 365-370.

McComas, A. J., Sica, R. E. P., Upton, A. R. M., and Petito, F. (1974). Sick motorneurons and muscle disease. Annals of the New York Academy of Sciences, 228, 261-279.

Moulds, R. F. W. (1977). A comparison of the effects of sodium thiocyanate and dantrolene sodium on an isolated mammalian skeletal muscle. British Journal of Pharmacology, 59, 129-136.

Moulds, R. F. W., and Denborough, M. A. (1974). A study of the action of caffeine, halothane, potassium chloride and procaine on normal human skeletal muscle. Clinical and Experimental Pharmacology and Physiology, 1, 197-209.

Moulds, R. F. W., and Denborough, M. A. (1974). Biochemical basis of malignant hyperpyrexia. British Medical Journal, 2, 241-244.

Redfern, P., and Thesleff, S. (1971). Action potential generation in denervated rat skeletal muscle. Acta Physiologica Scandinavica, 81, 557-564.

Thesleff, S. (1974). Physiological effects of denervation of muscle. Annals of the New York Academy of Sciences, 228, 89-103.

Weber, A. (1968). The mechanism of the action of caffeine on sarcoplasmic reticulum. Journal of General Physiology, 52, 760-772. 